Research Article

\title{
Comprehensive Assessment of the Effect of Water Pressure on the Development of Cracks in Gravity Concrete Dams
}

\author{
Hamed Safayenikoo (iD \\ Department of Civil Engineering, Chabahar Maritime University, Chabahar, Iran \\ Correspondence should be addressed to Hamed Safayenikoo; h.safayenikoo@cmu.ac.ir
}

Received 15 July 2021; Revised 31 July 2021; Accepted 12 August 2021; Published 29 August 2021

Academic Editor: S. Mahdi S. Kolbadi

Copyright (c) 2021 Hamed Safayenikoo. This is an open access article distributed under the Creative Commons Attribution License, which permits unrestricted use, distribution, and reproduction in any medium, provided the original work is properly cited.

\begin{abstract}
In recent years, extensive studies have been conducted to ensure the safety and stability of concrete dams. The development of numerical methods in considering more factors affecting the response of dams and also increasing the accuracy of calculation methods has played an important role in ensuring the safety of concrete dams. Therefore, one of the most important points in the design and analysis of concrete dams is to predict the location of cracks, expand it, investigate the phenomenon of hydraulic failure, consider the pressure caused by the infiltration of reservoir water into cracks and joints in static and dynamic states, and find solutions prevention of dam destruction due to this phenomenon. In the study of the effect of tensile strength, with increasing tensile strength, the reservoir water level increases at the beginning of cracking and the final reservoir water level increases, but there is no linear relationship between tensile strength and the two responses. In general, in examining the refractive energy parameter in each of the states with and without taking into account the water pressure inside the crack, the results of the mentioned models are slightly different from each other, but comparing the results shows that in nonlinear analysis considering water pressure inside the crack failure energy change has a greater impact on the results of these models.
\end{abstract}

\section{Introduction}

Nowadays, it is possible to formulate the dam-foundation system in order to consider parameters such as dam interaction, foundation, presence of joints in the dam body, cracking and crushing of concrete in tension and pressure, opening and closing and slipping of cracks, sediment effect, the study of the effect of rotating components earthquakes, and the like. Due to the existence and construction of large and small dams in the world, the need to use proper care in the design, construction, and safety of the dam is felt more than ever [1]. The finite element method has been considered by many researchers as a powerful method with many capabilities among various numerical methods, among which its capabilities include the ability of linear and nonlinear analysis of structures under arbitrary loading. The nonlinear behavior of the structure and the cracking of the dam body have been observed in numerical and laboratory analyses as well as experimental observations. Occurrence and spread of cracks in weighted concrete dams are possible in lift joints, dam bases, and places where sudden cross sections change. The presence of cracks in concrete dams constructed or in operation may jeopardize the stability of the dam and disrupt its operation [2]. Also, the growth and expansion of cracks in structures in contact with water have secondary consequences, including water infiltration into the crack. As a result, it changes the distribution of stresses, and by creating additional pressure inside the body, it leads to the expansion of cracks, and in structures such as dams, slipping of the separated parts will follow [3].

1.1. Literature Review. Due to the limitations of the analytical method to consider the effect of all effective factors and also the growth of computer technology, different numerical formulations were proposed for the analysis of the dam-pi-reservoir system; the finite element method is one of the most effective of these methods. To this end, Zienkiewicz proposed a finite element formulation for solid and fluid 
coupling system analysis [4]. Biot and Ruina examined the dynamic response of the dam system and reservoir by considering the finite elements for the dam body and the infinitely long components for the reservoir by assuming the vertical upstream part of the dam. Over time, the limitations of his proposed model were resolved $[5,6]$. With the aim of approximate modeling of refraction and reflection of waves in the bottom of the reservoir, Boone and Ingraffea \& Carter et al., proposed an energy absorption coefficient $a_{a b s}$ by reservoir bottom sediments $[7,8]$. In addition, Goodman et al. investigated the effects of sediment on the bottom of the reservoir by the finite element method by considering the sediment as a linear and incompressible viscoelastic body [9]. In all the works mentioned, the answers are expressed in the frequency domain. Due to the analytical limitations of the frequency domain and its nonapplication in nonlinear analysis, numerical and semianalytical methods in the time domain were performed by Bernard et al. and Bhattacharjee et al. $[10,11]$.

With conventional classical methods, concrete dams are designed for the condition that no part of the dam is stretched under normal loads [12]. The design method of traction removal is analytically quite acceptable. In this method, stability against slippage, overturning, no tensile stress in the heel, and body of the dam are the main design criteria, but in bulk concrete structures such as dams, due to the high volume of concreting and factors such as creep and thermal stresses due to hydration and small cracks. In the early stages of dam construction, the condition of not creating a tensile stress in the dam body is not a suitable criterion for the design and analysis of these structures [13].

Concrete is one of the semibrittle materials. After breaking again, the grains collapse and the structure does not collapse at once and there will be some resistance with decreasing stress in the structure. In other words, concrete is a heterogeneous body, and with the occurrence and expansion of cracks in it, the tensile strength gradually decreases with increasing strain until it reaches zero [14]. The application of nonlinear fracture mechanics in comparison with linear fracture mechanics in cracking analysis of concrete dams is much less due to the complexity of its application [15]. However, Visser used nonlinear fracture mechanics and a cracked model for two-dimensional analysis of the Quina weighted concrete dam. He also used fixed and rotating cracked models with different shear strength factors in Quina dam analysis. The water level diagram was drawn according to the displacement of the dam head in order to compare it with linear fracture mechanics and plasticity [16].

\section{Material and Methods}

2.1. Concrete Cracking Modes. For crack (i) at a point, the hardness of crack mode $I$ depend $D_{i}^{I}$ on parameters such as material fracture energy $G f$, tensile strength diagram shape, tensile strength $f t$, and crack bond width $h c$. Fracture energy and tensile strength are constant parameters of materials. Details of the width of the crack band are given in this section. The shape of the crack softness diagram in the first mode of concrete failure will significantly change the values of the first mode softness modulus and is one of the topics discussed. The softness diagram of the first mode can take different forms as shown in Figure 1. The hardness modulus of the first mode of local cracks can be calculated from

$$
D_{i, I}^{I}=\frac{E E_{s}}{E-E_{s}}=-\left(\frac{f_{t}^{2} h_{c}}{2 G_{f}}\right) .
$$

In this regard, Es, the modulus of strain softening, is shown in Figure 1. In Figures 2 and 3, En is the normal strain of cracked concrete in local coordinates, $S_{n}^{c r}$ is the normal crack stress in local coordinates, $e_{n n}^{c r}$ is the local normal crack stress, and $E_{n}^{f}$ is the final normal crack stress, after which the tensile stress disappears. Many laboratory studies have shown the true failure of concrete in a nonlinear form. Various softening models have been proposed for concrete, among which, the exponential softening model is in good agreement with the laboratory results, but due to the complexity in applied engineering. In this research, a two-line softening diagram has been used to approximate the true softening diagram by adjusting the values of two parameters $a_{1}$ and $a_{2}$ in accordance with Figure 2. In this research, the two-line strain-softening equation is developed based on the following equations:

$$
\begin{aligned}
G_{f}= & -\frac{h_{C}}{2}\left[\frac{\left(a_{1} f_{t}+f_{t}\right)\left(1-a_{1}\right) f_{t}}{D_{i, b I}^{I}}+\frac{a_{1}^{2} f_{t}^{2}}{a_{2} D_{i, b I}^{I}}\right] \\
& -\frac{f_{t}^{2} h_{C}}{2}\left[\frac{a_{2}+\left(1-a_{2}\right) a_{1}^{2}}{a_{2} D_{i, b I}^{I}}\right], \\
D_{i, b I}^{I}= & \frac{a_{2}+\left(1-a_{2}\right) a_{1}^{2}}{a_{2}}\left(-\frac{f_{t}^{2} h_{C}}{2 G_{f}}\right)=\frac{a_{2}+\left(1-a_{2}\right) a_{1}^{2}}{a_{2}} D_{i, I}^{I} .
\end{aligned}
$$

$a_{1}$ is defined as the part of tensile strength that is a factor for flat strain softening (the first mode softening modulus uses the slope of the second softening line slope) and $a_{2}$ is defined as the ratio of the second softening modulus to the first softening modulus. Due to the locking and engagement of grains and materials in the concrete slab, the shear modulus will not reach zero immediately after cracking. Therefore, shear stress can be developed on the next load on the crack plate [18]. In the past, Betacharaji et al. introduced the shear factor parameter to model the softening in cracked $\beta$ concrete. Experimental studies also showed that the shear modulus does not have constant values and depends on the normal crack strain. In this study, the softening in the shear is expressed in terms of the normal surface strains, and the shear reduction coefficient is derived from equations (4) and (5). Due to the above relations, the matrix of elasticity of 


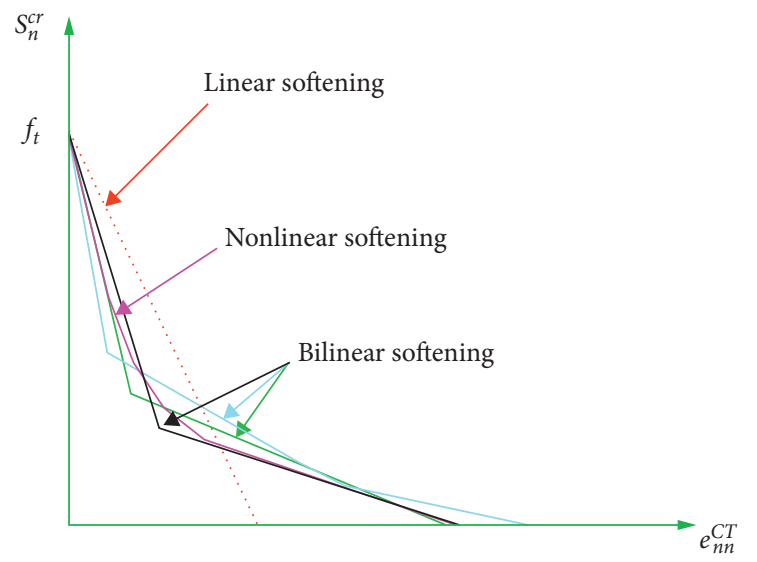

Figure 1: Types of softening diagrams [17].

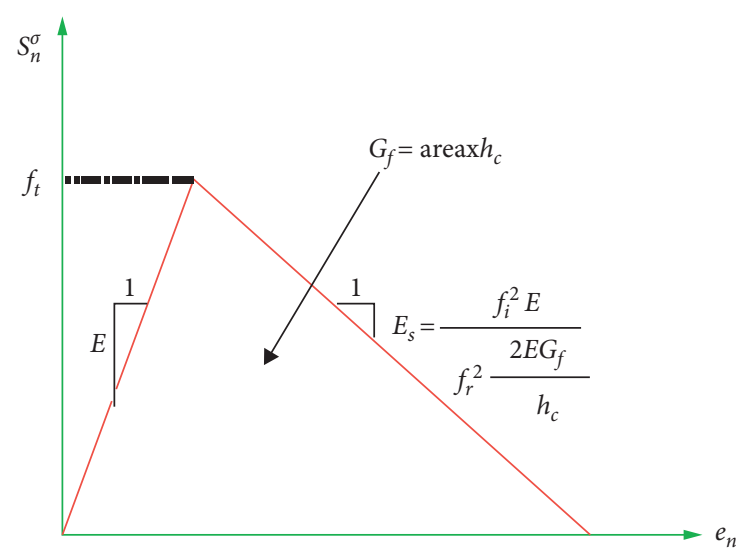

FIGURE 2: Linear rubber softens cracked concrete [17].

cracked concrete in local coordinates for rotational cracking is written as follows; then, with the help of the conversion matrix, this matrix is transferred to the original coordinates [19].

$$
\begin{aligned}
\beta & =\frac{1+v}{1-\eta v^{2}}\left(\frac{\eta \varepsilon_{\mathrm{n}}-\varepsilon_{s}}{\varepsilon_{n}-\varepsilon_{s}}-\eta v\right), \\
D n s & =\frac{E}{1-\eta v^{2}}\left[\begin{array}{ccc}
\eta & \eta v & 0 \\
\eta v & \eta & 0 \\
0 & 0 & \beta=\frac{1-\eta v^{2}}{2(1+v)}
\end{array}\right] .
\end{aligned}
$$

2.2. Bandwidth Crack. In the cracked model, cracks form in the element and propagate in an area dependent on the size of the element. It is assumed that the fracture process occurs in an area called the crack bandwidth [20]. Researchers have made various suggestions for this consideration. Geiger et al. introduced the crack bandwidth parameter of the material, which should be 3 to 10 times the maximum grain size. Betacharaji and Leger suggested the width of the crack band equal to the square root of the element [21]. In the present study, finer elements have been used in the area where there are cracks in order to correctly model and determine the crack path (Figure 1).

\section{Analysis and Discussion}

3.1. Verification. In order to perform the mathematical model calculations presented in Chapter 3 using the finite element method for concrete dams under the influence of weight, reservoir water pressure and water infiltration in leaving the computer program in FORTRAN language have been prepared. In order to evaluate the accuracy of the computer program prepared in this research, it is necessary to compare the results of the computer program in linear and nonlinear analysis with analytical and laboratory results. This section examines the accuracy of the formulation and performance of a computer program in three stages.

3.2. Slotted Cutting Beam. In order to investigate the performance of the computer program in the nonlinear behavior of materials and to predict the crack growth path, the shear beam with the initial gap under the two-point loading that was investigated in [22] by Betacharaji was considered according to Figure 4. Betacharji examined the sample in the laboratory and numerically. The geometric characteristics of the beam and its finite element model are shown in Figure 4. In Figure 4, the dimensions are in millimeters. The initial crack was marked with a blackened area and is in line with point $\mathrm{C}$. In the numerical study performed by him, the load was applied directly to points A and B with the ratio shown in Figure 4. The modulus of elasticity, Poisson's ratio, fracture energy, and tensile strength of this sample according to [23] were considered equal to $27.8 \mathrm{GPa}, 0.18,100 \mathrm{Nm}$, and 2.8 $\mathrm{MPa}$, respectively.

In the present study, the sample network was networked with 1300 eight-node elements. According to [24] and according to Figure 5, in order to study the crack path more precisely, for the networking of the sample, the size of the elements was reduced by approaching the initial gap of the model and smaller elements were used around the initial gap. The beam cracking profiles in [25] and the present study are shown in Figures 5. As can be seen in these figures, the cracked model in the present study follows a vertical path from the top of the gap to below the load site. According to the element used, the modeling of the model in the present study is largely consistent with the reference results [25]. Also, the differences in the response of the present study and the laboratory model can be related to the characteristics of materials and test conditions.

3.3. Pine Flat Finite Element Model. According to the materials presented in the second chapter of this dissertation, nonlinear static analysis including water pressure inside the crack for a low-weight concrete dam has not been done [26]. On the other hand, the dam has been selected as a case study in various topics such as seismic analysis and reviewed by various researchers. For this purpose, in the present study, the low-weight 


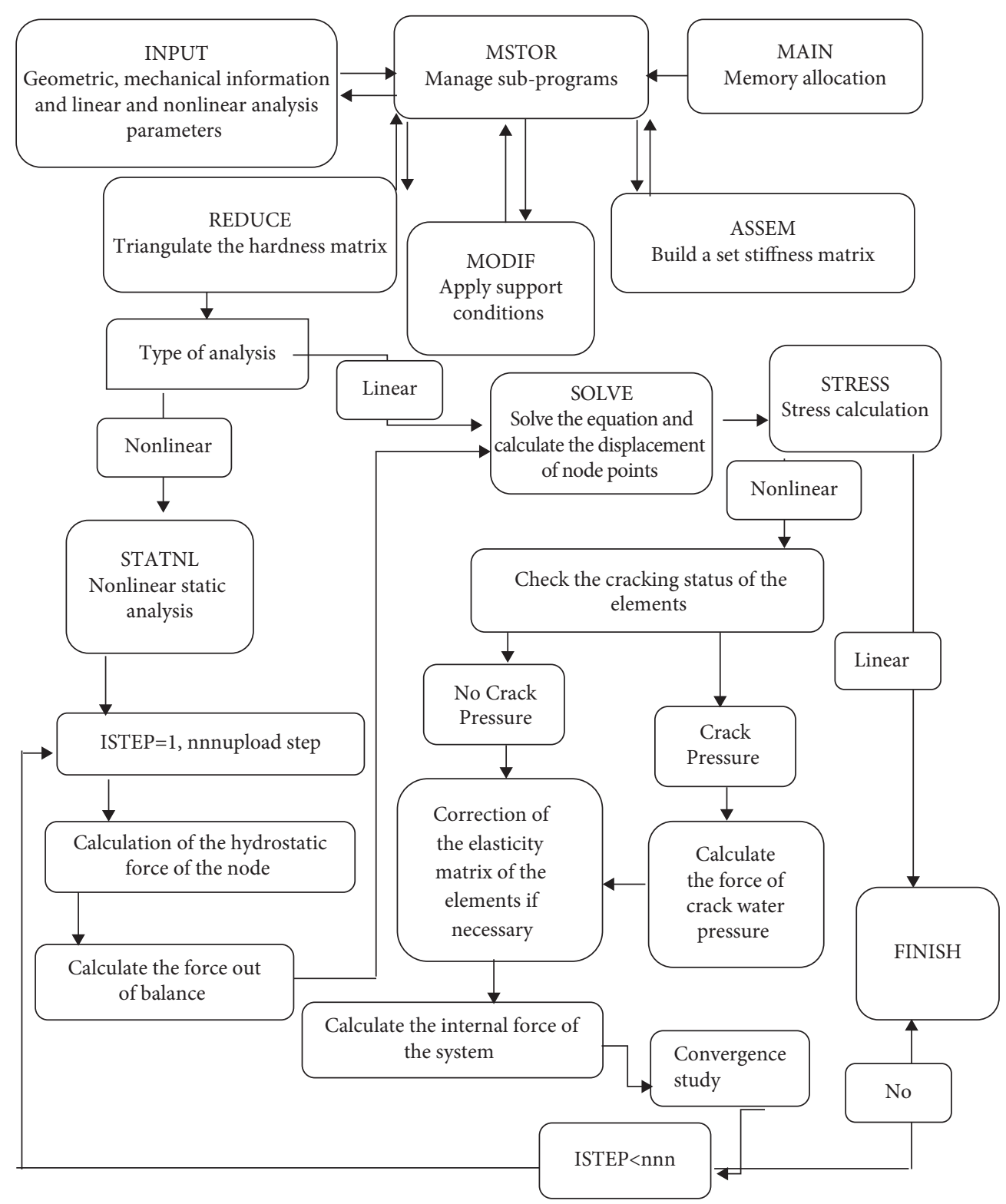

FIGURE 3: Computer program algorithm in determining nonlinear analysis response.
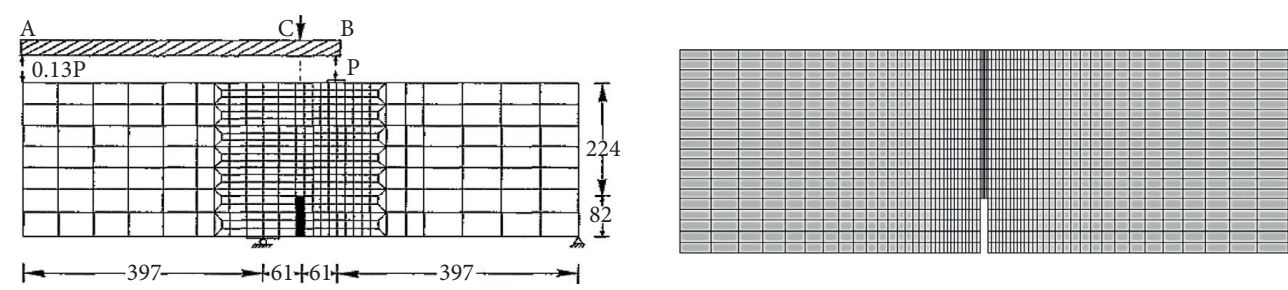

FIGURE 4: Finite element model of the shear beam with an initial gap under two-point loading in terms of (mm) (a) reference [25] and (b) the present study.

concrete dam has been considered as a case study, and the parameters of tensile strength and fracture energy in the no-state conditions taking into account the water pressure inside the crack have been investigated [27].
3.4. Investigation of Tensile Strength Parameter. In this section, the results of the study of tensile strength and fracture energy parameters in both cases with and without taking into account the water pressure inside the crack are 


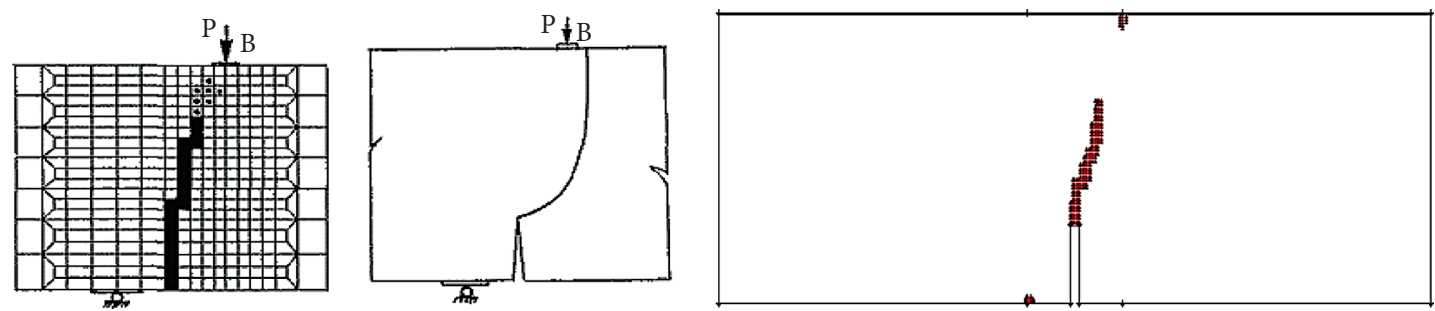

FIGURE 5: Shear beam cracking profiles in reference [25]: (a) laboratory model and (b) rotational crack model compared with those obtained by the proposed method.

presented along with the comparison of the results of these two cases [28]. As mentioned in Chapter 3 of this dissertation, in this study, the criterion for the onset of cracking is tensile strength, so it is necessary to investigate the effect of this parameter on the response of the structure [29]. For this purpose, five different models D1, D2, D3, D4, and D5 introduced in Table 1 were tested in two cases with and without taking into account the water pressure inside the crack [30]. Also, in order to investigate the effect of the tensile strength ratio on the responses, the response of each model was measured compared to the D4 model [4].

This section investigates the effect of the tensile strength parameter on the response of concrete dams without taking into account the water pressure inside the crack [31]. Figure 6 shows the horizontal displacement of the dam crown at different reservoir water levels for the five models [32]. The horizontal part in each of the diagrams in Figure 6 shows the final reservoir water level and the strength of the structure, which increases with increasing tensile strength, the final strength of the structure. As can be seen from this figure, at the water level of the reservoir less than 123 meters, the answers of the 5 mentioned models are the same and the diagrams coincide. However, at the water level of the reservoir of more than $123 \mathrm{~m}$, due to crack germination and its expansion, the difference in the response of the samples starts and continues until the final resistance of the reservoir [33]. Due to the high tensile strength in the D1 model and the onset of crack germination at a higher reservoir water level, the final reservoir water level in this model is significantly different from other models [34].

Table 1 presents the results of model analysis, and the results of each model were compared with the D4 model. According to the values reported in Table 1 and Figure 7, by changing the tensile strength, the reservoir water level changes at the beginning of cracking and increases with increasing the tensile strength [35]. In addition, the reservoir water level when cracking spreads is different in the five models, in each of the models $D 1, D 2, D 3, D 4$, and $D 5$ with $1.5,2.5,5,7$, and 6 meters increase in level, respectively. Reservoir water expands at the bottom relative to the reservoir water level when a crack germinates [36]. From the results presented in Table 1, it can be seen that with increasing tensile strength, the onset of crack germination occurs at a higher water level, but crack propagation at the dam floor occurs less as the reservoir water level increases [37].

As shown in Table 1, with increasing tensile strength, the maximum horizontal displacement of the dam crown increases, but a similar trend for crack length at the dam floor cannot be predicted [38]. The crack lengths of the dam floor in models D2 to D5 are slightly different from each other, but in model $D 1$, due to the high tensile strength, the crack length is approximately 1.5 times that of the other four models [39]. However, the cracking process is the same in the 5 models mentioned. As the water level of the reservoir increases, cracking occurs at the Pine Flat Dam and spreads until the final level of the reservoir water at a height of $99.5 \mathrm{~m}$ from the dam body, $2.5 \mathrm{~m}$ lower than the slope downstream of the dam that begins and expands, which increases the horizontal displacement of the dam crown [40]. In addition, there is no linear relationship between the ratio of the results of the mentioned models to the D4 model and the tensile strength ratio of each of these models. Figure 7 shows the crack profile at the final tank water level for each model [41].

This section examines the tensile strength parameter taking into account the water pressure inside the crack. Figure 8 shows the horizontal displacement of the dam crown at different reservoir water levels for the five models. As can be seen from Figure 8, at the water level of the reservoir less than 110 meters, the response of the models is the same and coincides with each other, but with increasing the water level of the reservoir, the difference in the behavior of each model begins and continues until the final resistance and the biggest difference is seen in the behavior of the $D 1$ model.

Table 2 presents the results of the analysis of the mentioned models. The results were also compared to the D4 model. According to the values reported in Table 2 and Figure 9 with the change of tensile strength, the water level of the tank changes during the germination of cracks and increases with increasing tensile strength. In addition, the reservoir water level varies as the crack propagates in these models. Crack propagation in each of $D 1, D 2, D 3, D 4$, and D5 models with $0.1,0.1,0.2,0.4$, and $0.5 \mathrm{~m}$ increase of tank water level compared to water level during germination, respectively, happens. According to the results presented in Table 2, with increasing tensile strength, the reservoir water level increases during crack germination, but crack propagation at the dam floor occurs less as the reservoir water level increases and the crack expands more rapidly. As the tensile strength increases, the crack length at the Pine Flat Dam decreases, but this trend cannot be predicted for the maximum displacement of the dam crown. As can be seen in Table 2, the maximum displacement of the dam crown changes with the change of tensile position, but there is no definite trend. The cracking process is the same in all five 
TABLE 1: Effect of tensile strength in NCP mode on different dam performance indicators.

\begin{tabular}{|c|c|c|c|c|c|}
\hline \multicolumn{2}{|c|}{ Model name } & \multirow{3}{*}{$\begin{array}{c}\begin{array}{c}D 1 \\
3\end{array} \\
131.2\end{array}$} & \multirow{3}{*}{$\begin{array}{c}\text { D2 } \\
2 \\
121\end{array}$} & \multirow{3}{*}{$\begin{array}{c}\text { D3 } \\
1.5 \\
115\end{array}$} & \multirow{3}{*}{$\begin{array}{c}\text { D4 } \\
1 \\
108\end{array}$} \\
\hline \multirow{3}{*}{ Reservoir water level } & & & & & \\
\hline & $H i(\mathrm{~m})$ & & & & \\
\hline & $\mathrm{Hi} / \mathrm{H} 4$ & 1.21 & 1.12 & 1.06 & 1 \\
\hline \multirow{2}{*}{ Ultimate resistance } & $(U \max ) i(\mathrm{~mm})$ & 87.5 & 57.25 & 45.28 & 37.54 \\
\hline & $(U \max ) i /(U \max ) 4$ & 2.33 & 1.52 & 1.2 & 1 \\
\hline \multirow{2}{*}{ Maximum displacement } & $L i(\mathrm{~m})$ & 52.68 & 38 & 32.12 & 32.11 \\
\hline & $L i / L 4$ & 1.64 & 1.18 & 1 & 1 \\
\hline
\end{tabular}

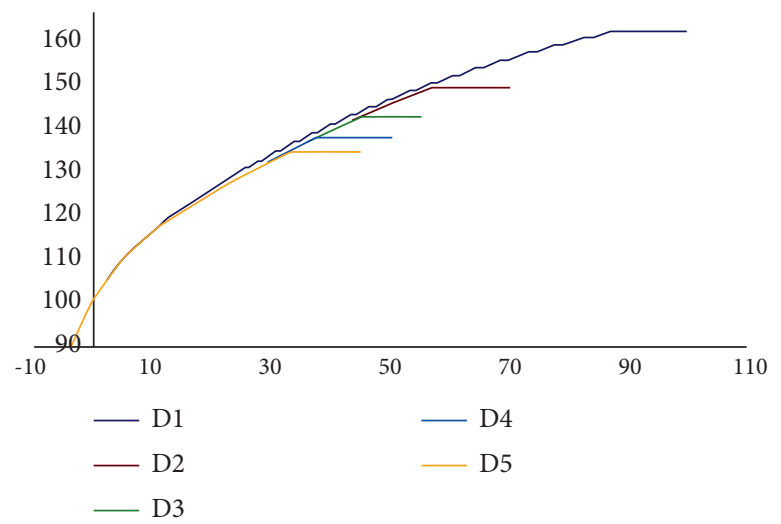

FIGURE 6: Investigation of tensile strength parameter on the response of the Pine Flat Dam in NCP mode.
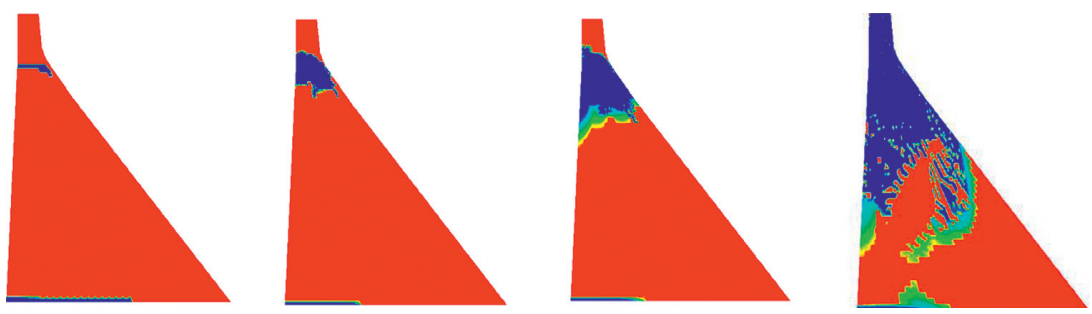

FIgURE 7: Cracking profile of Pine Flat Dam in the investigation of tensile strength parameter in NCP mode.

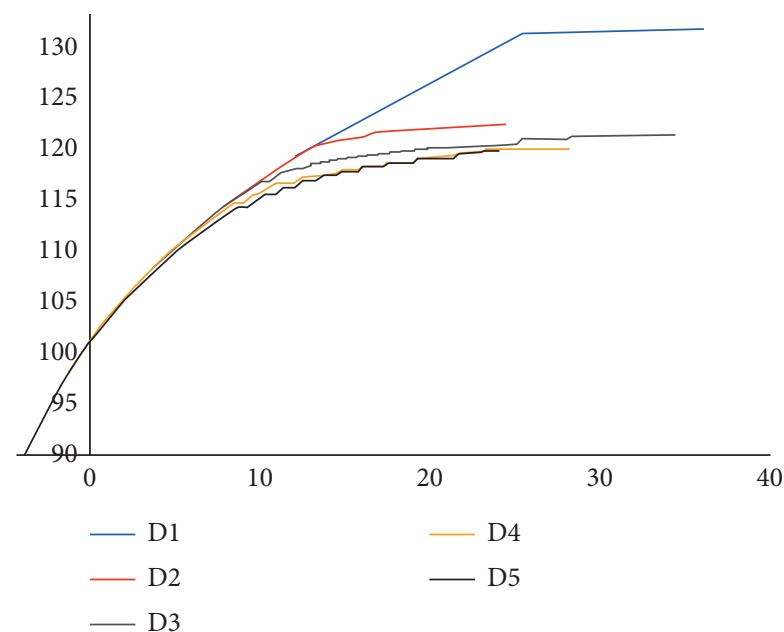

Figure 8: Investigation of tensile strength parameter on the response of the Pine Flat Dam in CP mode. models, in that with the increasing water level, cracking occurs only at the Pine Flat Dam. In addition, there is no linear relationship between the ratio of the results of the mentioned models to the D4 model and the tensile strength ratio of each of these models to the $D 4$ model. The cracking profile of the mentioned models is shown in Figure 9.

3.5. Comparison of Tensile Strength without and with Water Pressure inside the Crack. In order to examine the results of the previous two sections in more detail, this section compares the results of the analysis of the two states with and without taking into account the water pressure inside the crack. As can be seen from this table, for both cases, the reservoir water level is the same during crack germination and increases with increasing tensile strength. But with the beginning of the first crack, the conditions are created for water to penetrate into the crack, and the behavior of the dam changes. Taking into account the water pressure inside 
TABLE 2: Effect of tensile strength in CP mode on different dam performance indicators.

\begin{tabular}{|c|c|c|c|c|c|}
\hline \multicolumn{2}{|c|}{ Model name } & \multirow{2}{*}{$\begin{array}{c}\begin{array}{c}D 1 \\
3\end{array} \\
131.2\end{array}$} & \multirow{2}{*}{$\begin{array}{c}\text { D2 } \\
2 \\
121\end{array}$} & \multirow{2}{*}{$\begin{array}{c}\text { D3 } \\
1.5 \\
115\end{array}$} & \multirow{2}{*}{$\begin{array}{c}\begin{array}{c}D 4 \\
1\end{array} \\
108\end{array}$} \\
\hline \multirow[b]{2}{*}{ Reservoir water level } & $H i(\mathrm{~m})$ & & & & \\
\hline & $\mathrm{Hi} / \mathrm{H} 4$ & 1.21 & 1.12 & 1.06 & 1 \\
\hline \multirow{2}{*}{ Ultimate resistance } & $(U \max ) i(\mathrm{~mm})$ & 36.03 & 24.33 & 34.35 & 28.12 \\
\hline & $(U \max ) i /(U \max ) 4$ & 1.28 & 0.86 & 1.22 & 1 \\
\hline \multirow{2}{*}{ Maximum displacement } & $L i(\mathrm{~m})$ & 30 & 36 & 65.88 & 71.87 \\
\hline & $\mathrm{Li} / \mathrm{L} 4$ & 0.41 & 0.50 & 0.91 & 1 \\
\hline
\end{tabular}
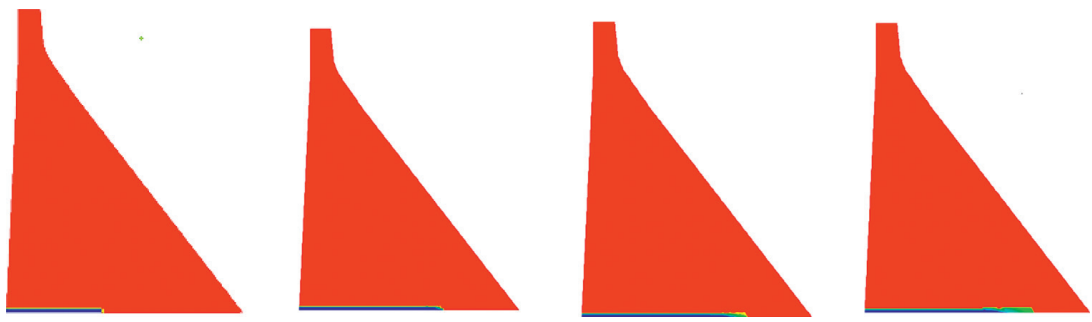

FIgURE 9: Cracking profile of Pine Flat Dam in investigation of tensile strength parameter in CP mode.

the crack, a force is formed in the crack that acts in the direction of the instability of the dam, as a result of which, the crack expands faster. In each of the models $D 1, D 2, D 3$, $D 4$, and $D 5$, the reservoir water level during crack expansion with taking into account the water pressure inside the crack compared to that without taking into account the water pressure inside the crack, respectively, 1.05, 1/21, 2.5, and 6 decreased by 2.2 and $0.93 \%$. Also, taking into account the water pressure inside the crack, the final resistance of each sample decreases significantly, in model $D 1$, it decreases by $19 \%$ to 131.82 meters, and for models $D 2, D 3, D 4$, and $D 5$, respectively, $18.28,16,15 / 16,13 / 16$, and $11.2 \%$ decrease is seen.

Taking into account the water pressure inside the crack, the difference in the final reservoir water level between model $D 2$ and $D 5$ increased from 14.9 to $2.6 \mathrm{~m}$. Also, in each of the models $D 1$ to $D 5$, the difference in reservoir water level during crack germination to the final reservoir water level of $0.98,0.97,0.77,60.2$, and $44.5 \%$, respectively, decreased, so in the mentioned case, the final level of the reservoir water occurs earlier than in the case without taking into account the water pressure inside the crack, and considering the effect of water pressure inside the crack has a great effect on the final strength. In model $D 1$, due to the high tensile strength, the water level of the tank during the germination of the crack is higher than the other four models. Also, in this model, in the no-state and with the water pressure inside the crack, respectively, for 1.5 and $0.1(\mathrm{~m})$ increase in reservoir water level, crack expansion occurs due to the high reservoir water level at the beginning of cracking and subsequent high pressure in the crack.

As mentioned in the previous two sections, the cracking process is completely different in these two cases, but in both cases, cracking occurs at the Pine Flat Dam with different lengths. Taking into account the water pressure inside the crack, the crack length at the dam floor decreases by $0.43 \%$ and $5.2 \%$ for models $D 1$ and $D 2$, respectively, and increases by $105.16,123.8$, and $104.94 \%$ for models $D 3, D 4$, and $D 5$, respectively. In addition, without taking into account the water pressure inside the crack, the maximum horizontal crack length of the dam floor occurs in model $D 1$ with the highest tensile strength, but with the calculation of water pressure inside the crack, the maximum crack length in the dam floor occurs in model D5 with the lowest tensile strength. Figure 10 shows the horizontal displacement of the dam crown at different reservoir water levels for the five models mentioned in both cases with and without taking into account the water pressure inside the crack. As shown in Figure 10, the behavior of the structure in both cases with and without taking into account the water pressure inside the crack before the onset of cracking is the same and the diagrams coincide. With the expansion and infiltration of water in the crack, the horizontal displacement of the dam crown increases, which is followed by a change in the behavior of the structure.

3.6. Investigation of Failure Energy Parameter. Failure energy is one of the important parameters in nonlinear analysis by nonlinear failure mechanics. This parameter was investigated by various researchers. Each researcher provided suggestions for the value of this parameter and the factors affecting it, some of which were mentioned in the second chapter of this dissertation. In the present study, four different models $D 2, D 6, D 7$, and $D 8$ introduced in Table 3 were considered in two cases with and without taking into account the water pressure inside the crack. Also, in order to investigate the effect of refractive energy ratio on the responses, the response of each model was measured compared to the $D 2$ model.

This section examines the failure energy parameter without taking into account the water pressure inside the crack. The horizontal displacement diagram of the dam crown at different reservoir water levels is shown in 

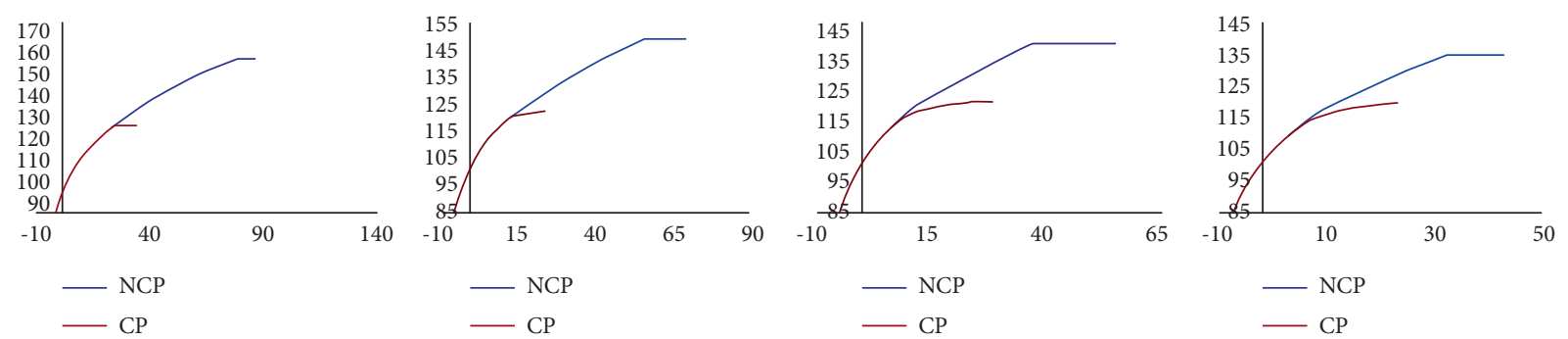

Figure 10: Comparison of horizontal displacement of the dam crown in NCP and CP modes of models D1 to D5 in the study of tensile strength parameter.

TABLE 3: Effect of failure energy in NCP mode on different dam performance indicators.

\begin{tabular}{|c|c|c|c|c|c|}
\hline \multirow{2}{*}{\multicolumn{2}{|c|}{ Model name }} & D5 & D6 & D7 & D8 \\
\hline & & 0.5 & 1 & 2 & 3.3 \\
\hline \multirow{2}{*}{ Reservoir water level } & $H i(\mathrm{~m})$ & 121.02 & 121.02 & 121.02 & 121.02 \\
\hline & $\mathrm{Hi} / \mathrm{H} 4$ & 1 & 1 & 1 & 1 \\
\hline \multirow{2}{*}{ Ultimate resistance } & $(U \max ) i(\mathrm{~mm})$ & 57.01 & 57.25 & 57.4 & 59.62 \\
\hline & $(U \max ) i /(U \max ) 4$ & 0.99 & 1 & 1.01 & 1.04 \\
\hline \multirow{2}{*}{ Maximum displacement } & $L i(\mathrm{~m})$ & 38.3 & 38 & 39 & 40.4 \\
\hline & $\mathrm{Li} / \mathrm{L} 4$ & 1.01 & 1 & 1.03 & 1.06 \\
\hline
\end{tabular}

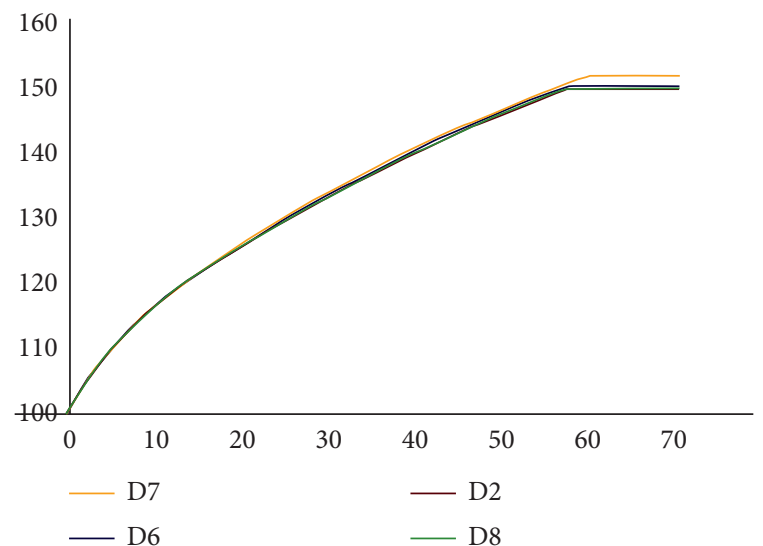

FIGURE 11: Investigation of the failure energy parameter on the response of the Pine Flat Dam in NCP mode.

Figure 11. The final tank water level can be seen for the models mentioned in this figure. As can be seen from this figure, for the $D 2, D 6$, and $D 8$ models, the responses are exactly the same, the change in refractive energy has no effect on the structural response, and the ultimate strength of all three models is about 150 meters. But in the D7 model, the final water level of the tank is about 1.5 meters higher than the other three models.

Table 3 presents the results of the mentioned models. According to the values presented in Table 3, the water level breakage energy did not change during crack germination and is the same for the four models. The results reported in Table 3 show that the change of fracture energy has no effect on water level during crack germination but affects the water level during crack expansion. With increasing fracture energy, the final crack length at the dam floor, maximum displacement of the horizontal crown of the dam, the final strength, and the cracking process of the mentioned models are almost the same. Figure 12 shows the cracking profile of the mentioned models [42].

The fracture energy parameter is investigated by taking into account the water pressure inside the crack in this section [43]. The horizontal displacement diagram of the dam crown at different reservoir water levels is shown in Figure 13. As can be seen from this figure, the final reservoir water level changes as the refractive energy changes. At water levels less than $120 \mathrm{~m}$ and before the start of germination, the displacement of the mentioned models has a good adaptation to each other, but with the beginning of germination, the difference in the response of the samples can be seen [44].

Table 4 presents the results of the analysis for each of the mentioned models. Taking into account the water pressure inside the crack, as reported in this table, there is a slight difference between the reservoir water level at the beginning of the crack germination and the final reservoir water level [45]. According to the results reported in this table, with the change of fracture energy, the reservoir water level did not change during crack germination and is the same in all four models, but there is a slight difference in reservoir water level when the crack expands at the dam floor in the model. D8, D2, D6, and D7 with $0.1,0.1,0.9$, and $2.5 \mathrm{~m}$ increases in reservoir water level compared to water level occurs during crack germination, respectively. As reported in Table 4, the maximum horizontal displacement of the dam crown occurs in the D6 model. Increasing the refractive energy from 75 to $300 \mathrm{~N} / \mathrm{m}$ increases the maximum horizontal displacement of the dam crown, but with increasing the refractive energy in the $D 7$ model to $500 \mathrm{~N} / \mathrm{m}$, the maximum horizontal displacement of the dam crown decreases. This trend is also seen in the length of cracks in the dam floor. Figure 14 shows the cracking profile of the mentioned models. 

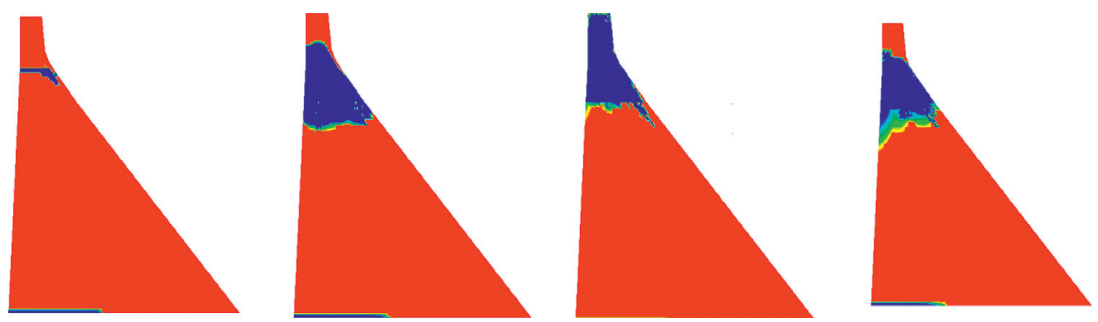

FIgURE 12: Cracking profile of Pine Flat Dam in the investigation of failure energy parameter in NCP mode.

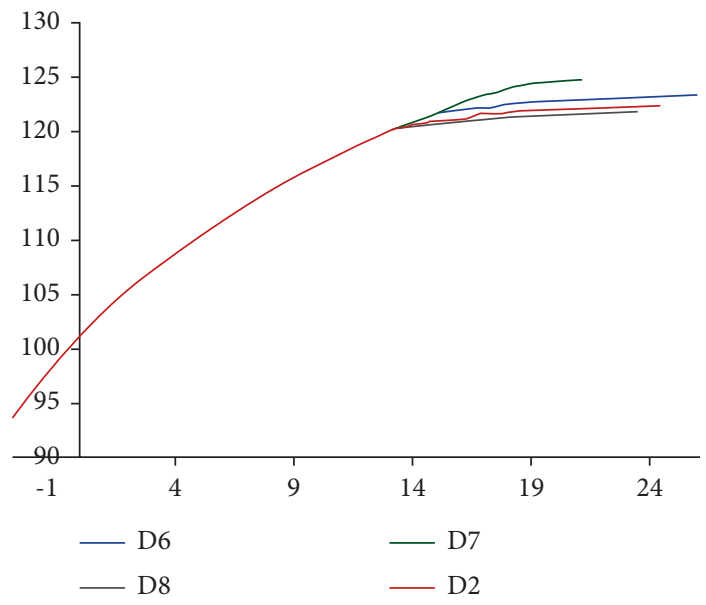

Figure 13: Investigation of the failure energy parameter on the response of the Pine Flat Dam in CP mode.

TABLE 4: Effect of failure energy in CP mode on different dam performance indicators.

\begin{tabular}{|c|c|c|c|c|c|}
\hline \multicolumn{2}{|c|}{ Model name } & D5 & D6 & D7 & D8 \\
\hline \multirow[b]{2}{*}{ Reservoir water level } & $H i(\mathrm{~m})$ & 121.02 & 121.02 & 121.02 & 121.02 \\
\hline & $\mathrm{Hi} / \mathrm{H} 4$ & 1 & 1 & 1 & 1 \\
\hline \multirow{2}{*}{ Ultimate resistance } & $(U \max ) i(\mathrm{~mm})$ & 23.4 & 24.33 & 25.78 & 21.09 \\
\hline & $(U \max ) i /(U \max ) 4$ & 0.94 & 1 & 1.06 & 0.86 \\
\hline \multirow{2}{*}{ Maximum displacement } & $\operatorname{Li}(\mathrm{m})$ & 34.44 & 36 & 41.93 & 26.95 \\
\hline & $\mathrm{Li} / \mathrm{L4}$ & 0.95 & 1 & 1.16 & 0.74 \\
\hline
\end{tabular}
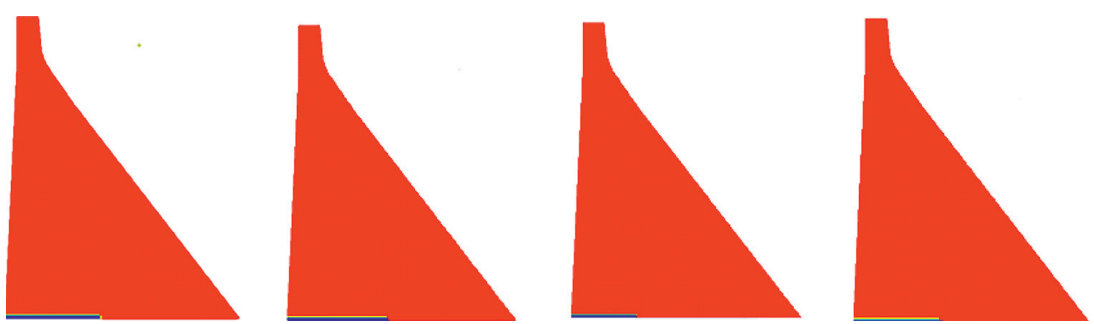

FIGURe 14: Cracking profile of Pine Flat Dam in the investigation of failure energy parameter in CP mode.

3.7. Comparison of Failure Energy Effect without and with Water Pressure inside the Crack. As can be seen from this table, the reservoir water level at the time of crack germination is the same for both. But with the onset of the first crack, conditions are created for water to penetrate into the crack and affect the behavior of the dam. With the infiltration of water in the crack, a force is formed in it that acts to create instability in the dam. In both cases, there is a slight difference in the water level as the crack expands. Taking into account the water pressure inside the crack in each of the models $D 8, D 2, D 6$, and $D 7$, the difference in water level from crack germination to the final level of reservoir water compared to that without considering the water pressure inside the crack is $97.21,95.13,88.31$, and $87.5 \%$ that has 

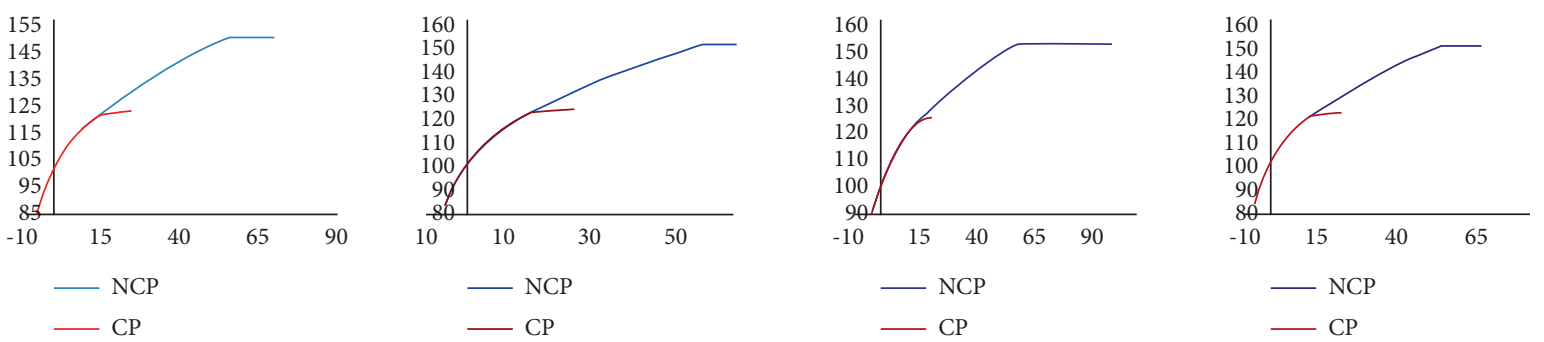

FIGURE 15: Comparison of horizontal displacement of the dam crown in NCP and CP modes of D2, D6, D7, and D8 models in the study of failure energy parameters.

decreased; in addition, with increasing fracture energy, the maximum horizontal displacement of the dam crown does not have a definite trend.

In these two cases, the process and behavior of cracking in the mentioned models are completely different, so that without taking into account the water pressure inside the crack, first cracking started at the dam floor; then, the final water level of the crack tank is 2.5 meters lower than the slope that starts downstream of the dam and expands at the same level. However, taking into account the water pressure inside the crack, cracking occurs only at the Pine Flat Dam and spreads with increasing the water level of the reservoir. Taking into account the water pressure inside the crack, the length of the dam floor crack in D8, D2, D6, and D7 models decreased by $9.98,5.23,7.5$, and $33.3 \%$, respectively, and the highest dam floor crack length occurred in model D6. Excluding the water pressure inside the crack, the maximum crack length occurred at the dam floor in the D7 model. The horizontal displacement diagram of the dam crown with increasing reservoir water level for each of the models is shown in Figure 15. As can be seen from the diagrams in Figure 15, the final capacity of the dam is significantly reduced by taking into account the water pressure inside the crack.

\section{Conclusion}

The program performance in nonlinear analysis in conditions with and without water pressure inside the crack was investigated. In order to investigate the element size and the effect of the parameters affecting the nonlinear fracture mechanics, sensitivity analysis was performed for each of the states with and without taking into account the water pressure inside the crack. Then, the parameters of tensile strength and fracture energy were investigated in the nostate conditions and taking into account the water pressure inside the crack under increasing stages of the reservoir water level. In addition, by changing the mentioned parameter, the crack length of the dam floor changes. Respectively, for each of the conditions with and without taking into account the water pressure inside the crack, the maximum crack length occurs in the model with the lowest and maximum tensile strength, but in general, it is not possible to conclude a specific trend to increase or decrease the crack floor length response. By changing the fracture energy, the reservoir water level does not change when cracking starts and the reservoir water level does not change with a certain trend when the crack expands. Also, the change of fracture energy is associated with the change of crack length, and the maximum crack length without taking into account the water pressure inside the crack occurs with a small difference in the model with the highest failure energy, but with the calculation of water pressure inside the crack, this parameter does not change. In addition, the maximum horizontal displacement of the dam crown does not follow a specific trend and is associated with increases and decreases.

\section{Symbols}

$D^{I I}$ : Hardness modulus of the second mode

$G$ : $\quad$ Elastic shear modulus

$b_{0}$ : Primary pore pressure

$p_{0}$ : Initial fluid pressure

$\{R\}$ : Internal force vector

$\{f\}$ : Volumetric force vector

$\alpha$ : Biot coefficient

$k_{T}$ : Total bulk module

$k_{S}$ : Solid section bulk module

$n$ : Porosity

$\delta_{i j}$ : Delta Kronecker

$P$ : $\quad$ Fluid pressure.

\section{Data Availability}

Requests for access to these data should be made to the corresponding author (e-mail address: h.safayenikoo@ cmu.ac.ir).

\section{Conflicts of Interest}

The author declares that there are no conflicts of interest regarding the publication of this study.

\section{References}

[1] J. Geertsma and F. De Klerk, "A rapid method of predicting width and extent of hydraulically induced fractures," Journal of Petroleum Technology, vol. 21, no. 12, p. 1, 1969.

[2] Z. P. BaZant and W. Thonguthai, "Pore pressure in heated concrete walls: theoretical prediction," Magazine of Concrete Research, vol. 31, no. 107, pp. 67-76, 1979.

[3] N. C. Huang and S. G. Russell, "Hydraulic fracturing of a saturated porous medium-I: general theory," Theoretical and Applied Fracture Mechanics, vol. 4, no. 3, pp. 201-213, 1985. 
[4] O. C. Zienkiewicz, Computational Geomechanics, Citeseer, Priceton, NJ, USA, 1999.

[5] M. A. Biot, "General theory of three-dimensional consolidation," Journal of Applied Physics, vol. 12, no. 2, pp. 155-164, 1941.

[6] A. Ruina, "Influence of coupled deformation-diffusion effects on the retardation of hydraulic fracture," in Proceedings of the 19th US Symposium on Rock Mechanics (USRMS), American Rock Mechanics Association, Reno, Nevada, May 1978.

[7] T. J. Boone and A. R. Ingraffea, "A numerical procedure for simulation of hydraulically-driven fracture propagation in poroelastic media," International Journal for Numerical and Analytical Methods in Geomechanics, vol. 14, no. 1, pp. 27-47, 1990.

[8] B. Carter, J. Desroches, A. J. Ingraffea, and P. A. Wawrzynek, "simulating fully 3D hydraulic fracturing," Modeling in geomechanics, John Wiley, Hoboken, NJ, USA, 2000.

[9] R. E. Goodman, B. Amadei, and N. Sitar, "Uplift pressure in crack below dam," Journal of Energy Engineering, vol. 109, no. 4, pp. 207-221, 1983.

[10] A. Bernard, I. Tissa, I. M. Douglas, and B Howard, "Estimation of uplift in cracks in older concrete gravity dams: effect of head losses in drain pipes on uplift," Journal of Energy Engineering ASCE, vol. 115, no. 1, 1989.

[11] S. Bhattacharjee, R. Tinawi, and P. Leger, "Poro-fracture analysis of concrete using a damage mechanics model," in Proceedings of the Fracture Mechanics of Concrete Structure, Zurich, Switzerland, July 1995.

[12] R. Tinawi and L. Guizani, "Formulation of hydrodynamic pressures in cracks due to earthquakes in concrete dams," Earthquake Engineering \& Structural Dynamics, vol. 23, no. 7, pp. 699-715, 1994.

[13] E. Bruhwiler and V. E. Saouma, "Water fracture interaction in concrete--Part I: fracture properties," Materials Journal, vol. 92, no. 3, pp. 296-303, 1995.

[14] E. Bruhwiler and V. E. Saouma, "Water fracture interaction in concrete--Part II: hydrostatic pressure in cracks," Materials Journal, vol. 92, no. 4, pp. 383-390, 1995.

[15] H.-W. Reinhardt, M. Sosoro, and X.-f. Zhu, "Cracked and repaired concrete subject to fluid penetration," Materials and Structures, vol. 31, no. 2, pp. 74-83, 1998.

[16] J. H. M. Visser, Extensile Hydraulic Fracturing of (Saturated) Porous Materials, TU Delft, Delft University of Technology, Delft, Netherlands, 1998.

[17] S. S. Bhattacharjee and P. Léger, "Fracture response of gravity dams due to rise of reservoir elevation," Journal of Structural Engineering, vol. 121, no. 9, pp. 1298-1305, 1995.

[18] P. Neittaanmäki, T. Rasssi, K. Majan, and O. Pironnueau, Influence of Water Pressure on Crack Propagation in concrete Dams, University of Napoli, Napoli, Italy.

[19] F. Javanmardi, P. Léger, and R. Tinawi, "Seismic structural stability of concrete gravity dams considering transient uplift pressures in cracks," Engineering Structures, vol. 27, no. 4, pp. 616-628, 2005.

[20] F. Barpi and S. Valente, "Modeling water penetration at damfoundation joint," Engineering Fracture Mechanics, vol. 75, no. 3-4, pp. 629-642, 2008.

[21] Y. W. Dong and Q. W. Ren, "An extended finite element method for modeling hydraulic fracturing in gravity dam," Shuili Xuebao, vol. 42, no. 11, pp. 361-1367, 2011.

[22] Q. Ren, Y. Dong, and T. Yu, "Numerical modeling of concrete hydraulic fracturing with extended finite element method," Science in China - Series E: Technological Sciences, vol. 52, no. 3, pp. 559-565, 2009.
[23] S. Secchi and B. Schrefler, "A method for 3-D hydraulic fracturing simulation," International Journal of Fracture, vol. 178, no. 1-2, pp. 245-258, 2012.

[24] S. Secchi and B. A. Schrefler, "Hydraulic fracturing and its peculiarities," Asia-Pacific Journal of Chemical Engineering, vol. 1, no. 1, p. 8, 2014.

[25] Y. Wang and J. Jia, "Experimental study on the influence of hydraulic fracturing on high concrete gravity dams," Engineering Structures, vol. 132, pp. 508-517, 2017.

[26] Z.-Y. Huo, G.-X. Qian, and D.-J. Zheng, "Monitoring methods of crack behavior in hydraulic concrete structure based on crack mouth opening displacement (CMOD)," The Open Civil Engineering Journal, vol. 8, no. 1, pp. 225-231, 2014.

[27] K. Wang, Q. Zhang, X. Xia, L. Wang, and X. Liu, “Analysis of hydraulic fracturing in concrete dam considering fluidstructure interaction using XFEM-FVM model," Engineering Failure Analysis, vol. 57, pp. 399-412, 2015.

[28] P. Manfredini, "Integrity assessments of a gravity dam with respect to pressurized crack propagation along the concrete foundation interface," 2000.

[29] S. Sha and G. Zhang, "Modeling of hydraulic fracture of concrete gravity dams by stress-seepage-damage coupling model," Mathematical Problems in Engineering, vol. 2017, Article ID 8523213, 15 pages, 2017.

[30] A. L. Warren, "Investigation of dam incidents and failures," Proceedings of the Institution of Civil Engineers - Forensic Engineering, vol. 164, no. 1, pp. 33-41, 2011.

[31] G. Bfer, "An isoparametric joint/interface element for finite element analysis," International Journal for Numerical Methods in Engineering, vol. 21, no. 4, pp. 585-600, 1985.

[32] S. S. Bhattacharjee and P. Léger, "Finite element modelling of the tensile strain softening behaviour of plain concrete structures," Engineering Computations, vol. 10, no. 3, pp. 205-221, 1993.

[33] L. K. Sarokolayi, B. N. Neya, and J. V. Amiri, "Nonlinear dynamic analysis of concrete gravity dams considering rotational component of ground motion," International Journal of Civil Engineering, vol. 13, pp. 16-29, 2015.

[34] E. P. Beer, E. R.. Johnston, J. T. DeWolf, and D. F. Mazurek, Mechanics of Materials, Springer, New York, NY, USA, 6th edition, 2011.

[35] S. Küçükarslan, "Time-domain dynamic analysis of damreservoir-foundation interaction including the reservoir bottom absorption," International Journal for Numerical and Analytical Methods in Geomechanics, vol. 28, no. 9, pp. 963-980, 2004.

[36] L. Simoni and S. Secchi, "Cohesive fracture mechanics for a multi-phase porous medium," Engineering Computations, vol. 20, no. 5/6, pp. 675-698, 2003.

[37] G. S. Monteiro, J. P. Neves and J. P. Gomes, Seismic monitoring system of baixo sabor and feiticeiro dams," Civil Engineering Journal, vol. 6, no. No 11, 2020.

[38] H. Pan and X. Jiang, "On the characteristics of ground motion and the improvement of the input mode of complex layered sites," Civil Engineering Journal, vol. 6, no. 5, 2020.

[39] S. M. Mousavimehr, O. A. Yamini, and M. R. Kavianpour, "Performance assessment of shockwaves of chute spillways in large dams," Shock and Vibration, vol. 2021, Article ID 6634086, 17 pages, 2021.

[40] R. Balamuralikrishnan and J. Saravanan, "Effect of addition of alccofine on the compressive strength of cement mortar cubes," Emerging Science Journal, vol. 5, no. 2, 2021. 
[41] M. Karalar and M. Cavusli, "Three dimensional seismic deformation-shear strain-swelling performance of AmericaCalifornia Oroville Earth-Fill Dam," Geomechanics and Engineering, vol. 24, no. 5, pp. 443-456, 2021.

[42] M. E. Kartal, M. Çavuşli, and M. Geniş, "3D nonlinear analysis of atatürk clay core rockfill dam considering settlement monitoring," International Journal of Geomechanics, vol. 19, no. 5, 2019.

[43] M. AminHariri-Ardebili, S. M. Seyed-Kolbadi, V. E. Saouma, and J. W. Salamon, L. K. Nuss, Anatomy of the vibration characteristics in old arch dams by random field theory," Engineering Structures, vol. 179, pp. 460-475, 2019.

[44] L. Furgani, M. A. Hariri-Ardebili, M. Meghella, and S. M. Seyed-Kolbadi, "On the dynamic capacity of concrete dams," Infrastructure, vol. 4, no. 3, p. 57, 2019.

[45] M. A. Hariri-Ardebili, S. M. Seyed-Kolbadi, V. E. Saouma, J. Salamon, and B. Rajagopalan, "Random finite element method for the seismic analysis of gravity dams," Engineering Structures, vol. 171, pp. 405-420, 2018. 